\title{
War exposure, 5-HTTLPR genotype and lifetime risk of depression
}

\author{
Sylvaine Artero, Jacques Touchon, Anne-Marie Dupuy, Alain Malafosse and Karen Ritchie
}

\section{Background}

In 1962 approximately 1.5 million French people living in Algeria were repatriated to France in very poor and often life-threatening conditions. These people constitute a cohort for the study of the long-term impact of gene-environment interaction on depression.

\section{Aims \\ To examine the interaction between a highly stressful life event and subsequent depression, and its modulation by a length polymorphism of the serotonin transporter gene (5-HTTLPR).}

\section{Method}

A community sample of people aged 65 years and over residing in the Montpellier region of the south of France was randomly recruited from electoral rolls. Genotyping was performed on 248 repatriated persons and 632 controls. Current and lifetime major and minor depressive disorders were assessed according to DSM-IV criteria.

\section{Results}

A significant relationship was observed between exposure to repatriation and subsequent depression $(P<0.002)$, but there was no significant effect of gene alone $(P=0.62)$. After controlling for age, gender, education, disability, recent life events and cognitive function, the gene-environment interaction (repatriation $\times 5$-HTTLPR) was globally significant $(P<0.002 ; \mathrm{OR}=3.21,95 \% \mathrm{Cl} 2.48-5.12)$. Individuals carrying the two short (s) alleles of 5-HTTLPR were observed to be at higher risk $(P<0.005 ; \mathrm{OR}=2.34,95 \% \mathrm{Cl} 1.24-4.32)$, particularly when repatriation occurred before age 35 years $(P<0.002 ; \mathrm{OR}=2.91,95 \% \mathrm{Cl} 1.44-5.88)$, but this did not reach significance in those who were older at the time of the event $(P=0.067)$.

\section{Conclusions}

The association between depression and war repatriation was significantly modulated by 5-HTTLPR genotype but this appeared to occur only in people who were younger at the time of exposure.

\section{Declaration of interest}

None.
Stressful life events and adverse life conditions have been shown to have an important role in the aetiology of depression. ${ }^{1,2}$ However, only a minority of people subjected to severe life stressors develop psychopathological symptoms, suggesting the existence of moderating factors. ${ }^{3}$ Previous research has suggested that genetic susceptibility may influence the association through gene-environment interaction $(G \times E)$, notably the locus 5-HTTLPR of the serotonin transporter gene SLC6A4. In children, adolescents and young adults, ${ }^{4-12}$ it has been observed that individuals with one or two short (s) alleles of the 5-HTTLPR polymorphism are more likely to develop depression and suicidal ideation after exposure to stress than individuals with one or two long (l) alleles. ${ }^{13}$ However, not all studies have found this interactive effect, and a meta-analysis conducted by Risch et al of 14 studies did not find a significant interaction between the serotonin transporter gene, life events and depression. ${ }^{14}$ Critics of this meta-analysis have pointed to possible problems of mismeasurement and non-standardisation of the environmental stressor, ${ }^{15}$ and the heterogeneity of the cohorts. In previous reports we did not find an association with the s allele in an elderly population in relation to either recent life events or childhood trauma, ${ }^{16,17}$ although an association has been found in an elderly Asian population. ${ }^{18}$ A number of factors might contribute to the conflicting results in elderly populations, notably reliance on recall of distant stressful events which may be subject to recall bias, particularly in people with high 'neuroticism' scores who tend to overreport stressors. ${ }^{19,20}$ Jacobs et al suggested that the trait of neuroticism might itself interact with 5-HTTLPR genotype and thus constitute a confounding factor, being in itself largely genetically determined. ${ }^{10}$ Before concluding that a 5-HTTLPR interaction effect is absent, it is perhaps worth considering whether this might only be evidenced by more precise and objective measures of environmental impact including war and major catastrophe, ${ }^{21}$ or might be specific to a restricted exposure window such as age at time of event. A further limiting factor in previous research has been the length of follow-up after the stressful event - commonly less than 5 years, although the pathogenic effects of traumatic life events have been shown to influence depression incidence throughout life. ${ }^{2}$ In this study we examined the impact of a common stressor on the incidence of depression between early adulthood and old age (37-40 years after the traumatic event) and the modulating effect of the 5-HTTLPR genotype. Our assumption is that among individuals exposed to a common traumatic event there will be individual differences in stress reactivity. The stressful event in this case was the repatriation of French citizens living in Algeria in 1962 as a result of the Algerian war (decolonisation conflict). As France was loosening its colonial hold in Africa during the 1960s, entire populations were affected. Over 1.5 million persons experienced profound dislocations. They were uprooted from their homes in Algeria, lost almost all their possessions and confronted poor living conditions on arrival. Many of these repatriated people came to Montpellier in the south of France, where this study was conducted. This cohort of repatriated individuals has thus been exposed to a common event known to be associated with exceptionally high rates of subsequent depression, ${ }^{22}$ and occurring at a specific point in time. The environmental component of the gene-environment interaction is thus more rigorously defined than in previous studies and the study design allows us to examine the effect of age at the time of the event and long-term mental health. 


\section{Method}

\section{Study design and sample}

The study was part of the Enquête de Santé Psychologique Risques, Incidence et Traitement (ESPRIT) project, a prospective general population study of lifetime psychiatric disorder in people over 65 years old in the Montpellier region of the south of France. The methodology of the study is described in detail elsewhere. ${ }^{23}$ Briefly, a random sample of 1863 community-dwelling persons over 65 years old was drawn from the 15 electoral rolls of the Montpellier district between March 1999 and February 2001. In 1962 about 80000 French repatriates arrived in Montpellier from Algeria, constituting at the time a fifth of the population. In our cohort $13 \%$ of participants had been repatriated from Algeria.

Participants were examined in a clinical research centre at the Gui de Chauliac Neurology Hospital in Montpellier. Those unable to come to the centre were examined in their homes. Participants completed a number of standardised questionnaires administered by trained staff and underwent clinical examination. Ethical approval for the ESPRIT study was granted by the ethics committee of the University Hospital of Kremlin-Bicêtre and all procedures were carried out with the written consent of the participants.

\section{Measurement of exposure}

We investigated 880 participants from the ESPRIT study (total $n=1863$ ) for whom 5-HTTLPR genotyping was available, all psychiatric and repatriation questionnaires were completed and who had no missing data on adjustment variables. We identified 248 repatriates, all of whom were White, from the Algerian war by a structured questionnaire relating to their experience of repatriation. Among the repatriated group we distinguished two levels of stress: those who experienced only repatriation to France, implying loss of possessions, unemployment and social disorganisation, and those who experienced not only repatriation but also at least one war-related traumatic event such as experiencing or witnessing torture, severe injury or death. We used the initial screening item for post-traumatic stress disorder from DSM-IV, ${ }^{24}$ and also required participants to recount the traumatic event in order to identify this subgroup $(n=62)$. Data from these two groups were analysed separately. A control group was constituted from 632 participants in the ESPRIT study who had not been repatriated and had not experienced any other form of trauma.

\section{Measurement of depression}

Lifetime and current depression were assessed by the Mini International Neuropsychiatric Interview (French version 5.00), validated in the general population setting, ${ }^{25}$ which provides DSM-IV diagnoses. For this study depression included both minor and major depressive episodes occurring after 1962, the former having a much higher prevalence in older populations. All cases were validated by a panel of psychiatrists masked to repatriation status. Cases of depression occurring before 1962 were eliminated from the analyses.

\section{Genotyping}

Blood samples for DNA collection for 5-HTTLPR genotyping were taken after the baseline clinical interview. The 5-HTTLPR insertion/deletion polymorphisms were assayed in two stages. Genomic DNA was extracted from white blood cells harvested from $15 \mathrm{ml}$ ethylenediamine tetra-acetic acid (EDTA) blood samples using DNA extraction kits from Amersham Pharmacia Biotech (New Jersey, USA). Subsequently, amplification of 5-HTTLPR was carried out using the primers HTTLPRF (GGCGTTGCCGCTCTGAATTGC) and HTTLPRR (GAGGGACTGAGCTGGACAACCCAC) in reaction mixtures with a total volume of $25 \mu \mathrm{l}$, with $200 \mathrm{ng}$ of genomic DNA, $10 \mathrm{pmol} / \mathrm{l}$ of the primers, $120 \mathrm{nmol} / \mathrm{l} \mathrm{dNTP}$, containing 7-deaza-dGTP instead of dGTP (Roche, Switzerland), 5\% DMSO (Sigma, Sigma-Aldrich, Lyon, France), $1.5 \mathrm{mmol} / \mathrm{l} \mathrm{MgCl}_{2}$ and $1.25 \mathrm{U}$ Taq polymerase (Eurobio, Brunschwig, Basel, Switzerland). Temperatures were $60^{\circ} \mathrm{C}$ for $30 \mathrm{~s}$ for annealing and $72^{\circ} \mathrm{C}$ for $1 \mathrm{~min}$ for extension. Polymerase chain reaction (PCR) products $(8 \mu \mathrm{l})$ were subjected to $45 \mathrm{~min}$ electrophoresis at $120 \mathrm{~V}$ in a PCR CheckIT gel (Elchrom Scientific AG, Switzerland) before being viewed under ultraviolet light to assess the 5-HTTLPR genotypes. An adenosine/guanine single nucleotide polymorphism (rs25531), located in the close vicinity of 5-HTTLPR, has recently been reported to modify transcriptional activity. ${ }^{26}$ On the basis of these in vitro functional data it has been proposed to recode the 5-HTTLPR/rs25531 allele

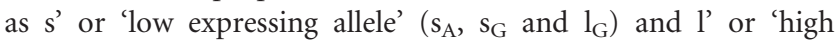
expressing allele' $\left(l_{\mathrm{A}}\right) \cdot{ }^{27}$ As this new allelic dichotomy still awaits replication in studies in vivo, we initially examined both allelic systems (s/l and $\left.s^{\prime} / l^{\prime}\right)$ in this study. Recoding did not significantly alter results so we report here only analyses relating to $s$ and 1 .

\section{Other measures}

Because of the age of the participants (over 65 years), cognitive impairment and disability were included as adjustment factors in statistical analyses. Cognitive functions were evaluated using the Benton Visual Retention Test, the Trail Making Test Part B, the Isaac Set test and the 'Five Words' test, a word recall test with both delayed free recall and recall with semantic prompts. ${ }^{28-31}$ These tests covered declarative verbal and spatial memory, central executive and semantic retrieval abilities. Cognitive impairment was defined as having a score in the lowest quartile range in relation to the relevant age- and education-matched comparison group. ${ }^{32}$ Impairment in the performance of everyday activities was assessed with the Lawton Instrumental Activities of Daily Living (IADL) and Katz Activities of Daily Living (ADL) scales, ${ }^{33,34}$ disability being defined as increased difficulty in at least one IADL or ADL item. As recent negative life events may confound the relationship with past events, the occurrence of negative events occurring in the past year (notably bereavement, rupture in significant relationships, financial and legal problems, dismissal, severe illness, loss of a highly valued object) was ascertained using the 12-item Gospel Oak questionnaire. ${ }^{35}$

\section{Statistical analysis}

Associations between stressful life events, 5-HTTLPR genotype and depression were initially measured by univariate analyses (chi-squared tests). Multivariate logistic regression was used to investigate the presence of $G \times E$ for depression occurring since repatriation. Models were fitted for the main effect of SLC6A4 (5-HTTLPR) genotype (included as $1 / 1, s / l$ and $s / s$ ) assuming a multiplicative effect for the $s$ allele $(1 / 10, s / 11, s / s \quad 2)$, and environmental effect was classified as 0 for the control group, 1 for the repatriation only group (Repat) and 2 for the repatriation plus trauma group (RepatT). The main effects of stress, genotype and interaction between genotype and stressor were investigated entering these variables as ordinal variables with Wald statistics analysed against one degree of freedom. All models were adjusted for age, gender, education, disability, cognitive function and recent 
life events. Statistical analyses were carried out using SPSS version 15.0 for Windows.

\section{Results}

The mean age of the 880 participants was 72.5 years $($ s.d. $=5.1)$ at baseline, and $62 \%$ were women. There was no significant age difference between the repatriated group $(73.2$ years, s.d. $=5.6)$ and the control group $(72.9$ years, s.d. $=5.5)$. Education levels were similar to those for the general elderly population $(23.4 \%$ low, $31.5 \%$ medium to low, $23.1 \%$ medium to high and $21.7 \%$ high). Lifetime prevalence of major or minor depression was $54 \%$ in the whole sample $(51.3 \%$ in the control group, $54.8 \%$ in the Repat group and $74.2 \%$ in the RepatT group). Lifetime prevalence of major depression alone was $23 \%$ in the whole sample $(21.4 \%$ in the control group, $23.3 \%$ in the Repat group and $37.3 \%$ in the RepatT group). At baseline the repatriate group showed a significantly higher rate of current depression and/or antidepressant use $(P<0.01) \quad(23.1 \%$ in the control group, $28.7 \%$ in the Repat group and $42.2 \%$ in the RepatT group).

The frequencies of the three 5-HTTLPR genotypes were 1/1 $27.2 \%(n=239), \mathrm{s} / 150.4 \%(n=444)$ and $\mathrm{s} / \mathrm{s} 22.4 \%(n=197)$, which is consistent with those found in other European populations with no deviation from Hardy-Weinberg equilibrium $\left(\chi^{2}=1.00\right.$, d.f. $\left.=1, P<0.41\right)$. As has been commonly observed previously, depression was associated with repatriation $(P<0.001)$ but not with genotype $(P=0.62)$ (Table 1$)$. Kendall's non-parametric test showed no correlation between 5-HTTLPR genotype and exposure to repatriation $(P=0.955)$.

Logistic regression was used to examine the effect of the main covariates and interaction, with depression as the dependent variable. All factors were entered as ordinal variables with Wald statistics and models adjusted for age, gender, education, disability, cognitive function and recent life events. War exposure and war exposure $\times 5$-HTTLPR were statistically significant, but there was no significant effect of gene alone (Table 2). Stratified analyses showed that the association between war exposure score and depression was significant for $\mathrm{s} / \mathrm{s}$ homozygotes and for heterozygotes but not for $1 / 1$ homozygotes (Table 2, Fig. 1). Sensitivity analysis conducted by combining the Repat and RepatT groups also showed a significant war exposure $\times 5$-HTTLPR effect (Wald 5.5, $P=0.01$ ).

We observed a significant third-order interaction term: war exposure $\times 5$-HTTLPR $\times$ age $(P<0.002) \quad($ Table 3$)$. Geneenvironment interaction was tested taking into account age by using stratified analyses with a 35-year cut-off (the mean age of the repatriated group in 1962). In this model, adjusted for covariates, war exposure $\times 5$-HTTLPR was statistically significant for repatriation occurring before the age of 35 years but not after that age (Table 3). The association between exposure and depression was significant for $\mathrm{s} / \mathrm{s}$ homozygotes and for heterozygotes but not for $1 / 1$ homozygotes (Table 3 ).

\section{Discussion}

To our knowledge this is the first study of gene-environment interaction that has used a stressful historical event as a common exposure as well as lifetime follow-up of incident depression. We observed a significant relationship between exposure to this highly stressful event and depression onset. ${ }^{4-11,13,18}$ As with previous research we found no significant relationship between depression and genotype; however, genotype was found to modulate the relationship between the stressful event and depression, with the presence of an s allele conferring higher risk. This relationship is further observed to be dose-related, with people homozygous for $\mathrm{s}$ being at higher risk than those heterozygous for this allele, and with no significantly greater risk in those homozygous for 1 . Participants with the $1 / 1$ genotype thus appear in our study to be resilient to stress-related depression. Most previous studies have combined data for heterozygotes and homozygotes in order to

\begin{tabular}{|c|c|c|c|c|c|}
\hline Source & $\begin{array}{l}\text { Total sample } \\
(n=880) n(\%)\end{array}$ & $\begin{array}{l}\text { No depression } \\
(n=408)^{\mathrm{a}} n(\%)\end{array}$ & $\begin{array}{c}\text { Depression } \\
(n=472)^{\mathrm{b}} n(\%)\end{array}$ & $\begin{array}{c}\chi^{2} \\
\text { (linear) }\end{array}$ & $P$ \\
\hline \multicolumn{6}{|l|}{ Stressor: war events } \\
\hline Control group & $632(71.8)$ & $308(75.5)$ & $324(68.6)$ & \multirow[t]{3}{*}{12.07} & \multirow[t]{3}{*}{$<0.002$} \\
\hline Repatriation only & $186(21.1)$ & $84(20.6)$ & $102(21.6)$ & & \\
\hline Repatriation plus trauma & $62(7.1)$ & $16(3.9)$ & $46(9.8)$ & & \\
\hline \multicolumn{6}{|l|}{ 5-HTTLPR } \\
\hline $\mathrm{s} / \mathrm{s}$ & $239(27.2)$ & $105(25.8)$ & $135(28.6)$ & \multirow[t]{3}{*}{0.96} & \multirow[t]{3}{*}{0.62} \\
\hline $\mathrm{s} / \mathrm{l}$ & $444(50.4)$ & 209 (51.2) & $234(49.6)$ & & \\
\hline |/| & $197(22.4)$ & $94(23.0)$ & $103(21.8)$ & & \\
\hline $\begin{array}{l}\text { I, long; s, short. } \\
\text { a. No depression group represer } \\
\text { b. Depression group represents }\end{array}$ & & & & & \\
\hline
\end{tabular}

\begin{tabular}{|c|c|c|c|}
\hline Models $^{a}$ & Wald & $P$ & OR $(95 \% \mathrm{Cl})$ \\
\hline War events & 12.71 & 0.001 & $2.58(1.49-4.38)$ \\
\hline 5-HTTLPR & 1.43 & 0.232 & $1.23(0.92-2.14)$ \\
\hline War events $\times 5$-HTTLPR & 13.22 & 0.002 & $3.21(2.48-5.12)$ \\
\hline \multicolumn{4}{|c|}{ Association between war events and depression } \\
\hline s/s genotype & 7.31 & 0.005 & $2.34(1.24-4.32)$ \\
\hline s/I genotype & 7.91 & 0.004 & $1.64(1.16-2.31)$ \\
\hline I/I genotype & 0.42 & 0.514 & $1.18(0.72-1.96)$ \\
\hline
\end{tabular}




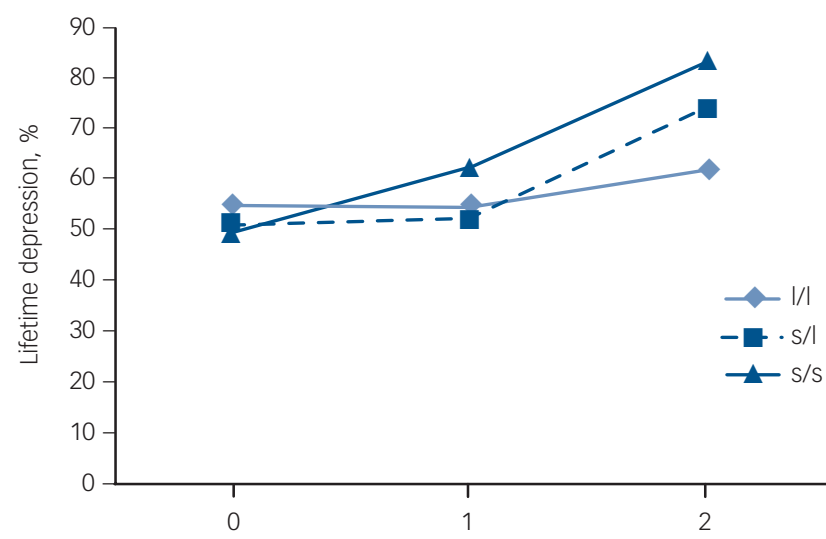

Fig. 1 Interaction between the genotypes (s/s, s/l, I/I) and number of war events with regard to depression: 0 , control group; 1 , repatriation only group; 2 , repatriation plus war trauma group.

maximise statistical power; the few studies that have differentiated these have reported a similar intermediary position, ${ }^{10,13,36}$ or alternatively a dominant $s$ effect, ${ }^{18,37,38}$ although two studies reported a recessive $s^{11,39}$

We also examined the possibility that age at time of exposure might have an effect on vulnerability to depression. Given that our source population was adult at the time of exposure, we were not able to examine an extensive age range, but only a dichotomous classification of under and over 35 years of age at the time of repatriation. We observed exposure gene effects to be stronger when the exposure occurred at the younger age, and to lose significance above age 35 years. Our findings raise the possibility that younger adults may be more vulnerable to depression following exposure to repatriation, and that furthermore there may be a gene-environment effect that diminishes with age. These observations should be considered as preliminary. Unfortunately, from our data it was not possible to determine the exact age range at which people are most vulnerable or at what age the interaction effect begins to diminish, if indeed it does. Kim et al found the presence of an $\mathrm{s}$ allele to increase risk of major and minor depression in elderly people after stressful life events, ${ }^{18}$ whereas a British study from the European Prospective Investigation into Cancer (EPIC) with a broader age range (41-80 years) found no increased risk linked to genotype. ${ }^{40}$ Within our own cohort, previous analyses suggested that the s allele has no interactive effect in relation to recent life events and late-onset depression, with a tendency rather for the 1 allele to increase vulnerability. ${ }^{16}$ In a further study we observed that the association between late-onset depression and adverse childhood environment was also increased in the presence of an 1 allele; ${ }^{17}$ however, data were not available to determine whether this was still the case for depression occurring at younger ages closer to the event.

Our study does not resolve the ongoing debate as to whether 5-HTTLPR genotype has a modulating effect on the relationship between life events and depression, but it does suggest that, should this be the case, the relationship may be more complex than previous study designs have anticipated, depending on the age of exposure, the type of exposure (severity of the life event and also its chronicity) and depression subtype (late or early onset). The role of the 1 allele in relation to late-onset depression also remains unclear. This study does not enable us to reach a conclusion with regard to these factors, but does indicate the importance of further exploring the effects of age and exposure type in relation to genetic vulnerability in future studies.

\section{Strengths and limitations}

This study has a number of strengths. Participants were exposed to a common event (repatriation) at a given time point, thus reducing recall bias; the temporal relationship between exposure to the stressful event and major depression onset was known and limited to hypotheses of one-way causality; the diagnosis of depression was made with a standardised structured interview, not a self-administered questionnaire as has been the case with many previous studies; lifetime depression onset was known, thus permitting us to assess the impact of the stressor over a period of 40 years (studies with short-term follow-up risk type 2 errors due

\begin{tabular}{|c|c|c|c|}
\hline Models $^{a}$ & Wald & $P$ & OR $(95 \% \mathrm{Cl})$ \\
\hline War events $\times 5-H T T L P R \times$ age & 10.01 & 0.002 & $1.2(1.1-1.4)$ \\
\hline \multicolumn{4}{|l|}{ War events } \\
\hline Age $<35$ years $(n=442)$ & 10.66 & 0.001 & $1.73(1.25-2.4)$ \\
\hline Age $\geqslant 35$ years $(n=438)$ & 2.3 & 0.129 & $1.33(0.92-1.91)$ \\
\hline \multicolumn{4}{|l|}{ 5-HTTLPR } \\
\hline Age $<35$ years $(n=442)$ & 1.81 & 0.178 & $0.86(0.69-1.07)$ \\
\hline Age $\geqslant 35$ years $(n=438)$ & 0.69 & 0.405 & $0.91(0.73-1.13)$ \\
\hline \multicolumn{4}{|l|}{ War events $\times 5$-HTTLPR } \\
\hline Age $<35$ years $(n=442)$ & 10.44 & 0.001 & $1.29(1.11-1.5)$ \\
\hline Age $\geqslant 35$ years $(n=438)$ & 3.34 & 0.067 & $1.17(0.98-1.39)$ \\
\hline \multicolumn{4}{|c|}{$\begin{array}{l}\text { Association between war events and depression } \\
\text { s/s genotype }\end{array}$} \\
\hline Age $<35$ years $(n=120)$ & 8.87 & 0.002 & $2.91(1.44-5.88)$ \\
\hline Age $\geqslant 35$ years $(n=119)$ & 2.88 & 0.089 & $2.02(0.9-4.44)$ \\
\hline \multicolumn{4}{|l|}{ s/l genotype } \\
\hline Age $<35$ years $(n=224)$ & 3.92 & 0.047 & $1.57(1.04-2.45)$ \\
\hline Age $\geqslant 35$ years $(n=220)$ & 0.62 & 0.430 & $1.22(0.74-2.03)$ \\
\hline \multicolumn{4}{|l|}{ |// genotype } \\
\hline Age <35 years $(n=99)$ & 1.23 & 0.267 & $1.55(0.72-3.36)$ \\
\hline Age $\geqslant 35$ years $(n=98)$ & 0.07 & 0.785 & $0.89(0.4-2.01)$ \\
\hline
\end{tabular}


to delayed depression onset); lifetime prevalence of depression was slightly higher $(54 \%)$ in our sample than in other European countries, ${ }^{23}$ giving sufficient statistical power to examine interaction effects which require a sample size four times greater than that necessary to detect the principal effect (environment). ${ }^{41}$

It is important to note, however, that our study has an important limitation in that past episodes of depression were evaluated retrospectively, so that time of onset could only be estimated by reference to concurrent events. Although we required validation of cases from a panel of psychiatrists, this was increasingly difficult with early-onset cases. Retrospective diagnosis, even when based on DSM criteria, has been shown elsewhere to lead to an underestimation of prevalence, ${ }^{42}$ which in our study would reduce the true significance of the association between exposure and depression and the genetic interaction. Although reporting of depressive symptoms is open to recall bias, everyday clinical practice depends largely on this method.

\section{Concluding remarks}

Our findings support the large body of existing literature that shows repatriation, immigration and refugee status to be significant risk factors for depression. In accordance with previous studies we found no direct relationship between depression and 5-HTTLPR genotype; however, participants who were under 35 years old at the time of the exposure were observed to report depression more frequently in their lifetime, and this risk further increased in the presence of an s allele. This relationship appears moreover to be dose-dependent, increasing with the number of $s$ alleles. In cases where populations are exposed to this type of social trauma, our findings also suggest that younger adults with an s allele may be particularly vulnerable, and therefore possibly a priority group for intervention.

\footnotetext{
Sylvaine Artero, PhD, Jacques Touchon, MD, Anne-Marie Dupuy, MD, Institut National de la Santé et de la Recherche Médicale (INSERM) U1061, and Montpellier University 1, Montpellier, France; Alain Malafosse, MD, PhD, INSERM U1061, University 1, Montpellier, France; Alain Malafosse, MD, PhD, INSERM U1061,
Montpellier, France, and Faculty of Medicine, University of Geneva, Switzerland; Karen Ritchie, PhD, INSERM U1061, Montpellier University 1, Montpellier, France, and Faculty of Medicine, St Mary's Hospital, Imperial College London, UK

Correspondence: Sylvaine Artero, INSERM U1061, Neuropsychiatry: Epidemiological and Clinical Research, La Colombière Hospital, 34093 Montpellier cedex 5, France. Email: sylvaine.artero@inserm.fr

First received 1 Oct 2010, final revision 12 Dec 2010, accepted 23 Feb 2011
}

\section{Funding}

The Enquête de Santé Psychologique - Risques, Incidence et Traitement (ESPRIT) project is financed by the regional government of Languedoc-Roussillon, the Agence Nationale de la Recherche and an unconditional grant from Novartis.

\section{References}

1 Mollica RF, Sarajlic N, Chernoff M, Lavelle J, Vukovic IS, Massagli MP. Longitudinal study of psychiatric symptoms, disability, mortality, and emigration among Bosnian refugees. JAMA 2001; 286: 546-54.

2 Steel Z, Silove D, Phan T, Bauman A. Long-term effect of psychological trauma on the mental health of Vietnamese refugees resettled in Australia: a population-based study. Lancet 2002; 360: 1056-62.

3 Goldberg EL, Comstock GW. Epidemiology of life events: frequency in general populations. Am J Epidemiol 1980; 111: 736-52.

4 Kaufman J, Yang BZ, Douglas-Palumberi H, Houshyar S, Lipschitz D, Krystal $\mathrm{JH}$, et al. Social supports and serotonin transporter gene moderate depression in maltreated children. Proc Natl Acad Sci U S A 2004; 101: 17316-21.

5 Eley TC, Sugden $K$, Corsico A, Gregory AM, Sham P, McGuffin P, et al. Gene-environment interaction analysis of serotonin system markers with adolescent depression. Mol Psychiatry 2004; 9: 908-15.
6 Sjoberg RL, Nilsson KW, Nordquist N, Ohrvik J, Leppert J, Lindstrom L, et al. Development of depression: sex and the interaction between environment and a promoter polymorphism of the serotonin transporter gene. Int J Neuropsychopharmacol 2006; 9: 443-9.

7 Cervilla JA, Molina E, Rivera M, Torres-Gonzalez F, Bellon JA, Moreno B, et al. The risk for depression conferred by stressful life events is modified by variation at the serotonin transporter 5HTTLPR genotype: evidence from the Spanish PREDICT-Gene cohort. Mol Psychiatry 2007; 12: 748-55.

8 Zalsman G, Huang YY, Oquendo MA, Burke AK, Hu XZ, Brent DA, et al. Association of a triallelic serotonin transporter gene promoter region (5-HTTLPR) polymorphism with stressful life events and severity of depression. Am J Psychiatry 2006; 163: 1588-93.

9 Grabe $\mathrm{HJ}$, Lange $\mathrm{M}$, Wolff $\mathrm{B}$, Volzke $\mathrm{H}$, Lucht $\mathrm{M}$, Freyberger $\mathrm{HJ}$, et al. Mental and physical distress is modulated by a polymorphism in the $5-\mathrm{HT}$ transporter gene interacting with social stressors and chronic disease burden. Mol Psychiatry 2005; 10: 220-4.

10 Jacobs N, Kenis G, Peeters F, Derom C, Vlietinck R, van Os J. Stress-related negative affectivity and genetically altered serotonin transporter function: evidence of synergism in shaping risk of depression. Arch Gen Psychiatry 2006; 63: 989-96.

11 Kendler KS, Kuhn JW, Vittum J, Prescott CA, Riley B. The interaction of stressful life events and a serotonin transporter polymorphism in the prediction of episodes of major depression: a replication. Arch Gen Psychiatry 2005; 62: 529-35.

12 Xie $\mathrm{P}$, Kranzler $\mathrm{HR}$, Poling J, Stein $\mathrm{MB}$, Anton RF, Brady $\mathrm{K}$, et al. Interactive effect of stressful life events and the serotonin transporter 5-HTTLPR genotype on posttraumatic stress disorder diagnosis in 2 independent populations. Arch Gen Psychiatry 2009; 66: 1201-9.

13 Caspi A, Sugden K, Moffitt TE, Taylor A, Craig IW, Harrington H, et al. Influence of life stress on depression: moderation by a polymorphism in the 5-HTT gene. Science 2003; 301: 386-9.

14 Risch N, Herrell R, Lehner $T$, Liang $K Y$, Eaves L, Hoh J, et al. Interaction between the serotonin transporter gene (5-HTTLPR), stressful life events, and risk of depression: a meta-analysis. JAMA 2009; 301: 2462-71.

15 Koenen KC, Galea S. Gene-environment interactions and depression. JAMA 2009; 302: 1859 [author reply 1861-2].

16 Power T, Stewart R, Ancelin ML, Jaussent I, Malafosse A, Ritchie K. 5-HTTLPR genotype, stressful life events and late-life depression: no evidence of interaction in a French population. Neurobiol Aging 2010; 31: 886-7.

17 Ritchie K, Jaussent I, Stewart R, Dupuy AM, Courtet P, Ancelin ML, et al. Association of adverse childhood environment and 5-HTTLPR genotype with late-life depression. J Clin Psychiatry 2009; 70: 1281-8.

18 Kim JM, Stewart R, Kim SW, Yang SJ, Shin IS, Kim YH, et al. Interactions between life stressors and susceptibility genes (5-HTTLPR and BDNF) on depression in Korean elders. Biol Psychiatry 2007; 62: 423-8.

19 Kessler RC, Magee WJ. Childhood adversities and adult depression: basic patterns of association in a US national survey. Psychol Med 1993; 23 679-90.

20 Van Os J, Jones PB. Early risk factors and adult person-environment relationships in affective disorder. Psychol Med 1999; 29: 1055-67.

21 Uher R, McGuffin P. The moderation by the serotonin transporter gene of environmental adversity in the etiology of depression: 2009 update. $\mathrm{Mol}$ Psychiatry 2010; 15: 18-22.

22 Lindert J, Ehrenstein OS, Priebe S, Mielck A, Brahler E. Depression and anxiety in labor migrants and refugees - a systematic review and metaanalysis. Soc Sci Med 2009; 69: 246-57.

23 Ritchie K, Artero S, Beluche I, Ancelin ML, Mann A, Dupuy AM, et al. Prevalence of DSM-IV psychiatric disorder in the French elderly population. Br J Psychiatry 2004; 184: 147-52.

24 American Psychiatric Association. Diagnostic and Statistical Manual of Mental Disorders (4th edn) (DSM-IV). APA, 1994.

25 Lecrubier Y, Sheehan D, Weiller E, Amorim P, Bonara I, Sheehan K, et al. The Mini International Neuropsychiatric Interview (MINI), a short diagnostic interview: reliability and validity according to the CIDI. Eur Psychiatry 1997; 12: $232-41$.

26 Wendland JR, Martin BJ, Kruse MR, Lesch KP, Murphy DL. Simultaneous genotyping of four functional loci of human SLC6A4, with a reappraisal of 5-HTTLPR and rs25531. Mol Psychiatry 2006; 11: 224-6.

27 Hu X, Oroszi G, Chun J, Smith TL, Goldman D, Schuckit MA. An expanded evaluation of the relationship of four alleles to the level of response to alcohol and the alcoholism risk. Alcohol Clin Exp Res 2005; 29: 8-16.

28 Benton A. Manuel pour l'application du test de retention visuelle. Applications cliniques et experimentales. Centre de Psychologie Appliqué, 1965 
29 Reitan R. Validity of the Trail Making Test as an indicator of organic brain damage. Percept Mot Skills 1965; 8: 271-6.

30 Isaac B, Kennie AT. The Set test as an aid to the detection of dementia in old people. Br J Psychiatry 1973; 123: 467-70.

31 Dubois B, Touchon J, Portet F, Ousset PJ, Vellas B, Michel B. 'The 5 words': a simple and sensitive test for the diagnosis of Alzheimer's disease [in French]. Presse Med 2002; 31: 1696-9.

32 Artero S, Ancelin ML, Portet F, Dupuy A, Berr C, Dartigues JF, et al. Risk profiles for mild cognitive impairment and progression to dementia are gender specific. J Neurol Neurosurg Psychiatry 2008; 79: 979-84.

33 Lawton MP. Scales to measure competence in everyday activities. Psychopharmacol Bull 1988; 24: 609-14.

34 Katz S, Ford AB, Moskowitz RW, Jackson BA, Jaffe MW. Studies of illness in the aged. The index of ADL: a standardized measure of biological and psychosocial function. JAMA 1963; 185: 914-9.

35 Harwood RH, Prince MJ, Mann AH, Ebrahim S. The prevalence of diagnoses, impairments, disabilities and handicaps in a population of elderly people living in a defined geographical area: the Gospel Oak project. Age Ageing 1998; 27: 707-14.
36 Wilhelm K, Mitchell PB, Niven H, Finch A, Wedgwood L, Scimone A, et al. Life events, first depression onset and the serotonin transporter gene. Br J Psychiatry 2006; 188: 210-5.

37 Hariri AR, Drabant EM, Munoz KE, Kolachana BS, Mattay VS, Egan MF, et al. A susceptibility gene for affective disorders and the response of the human amygdala. Arch Gen Psychiatry 2005; 62: 146-52.

38 Heinz A, Braus DF, Smolka MN, Wrase J, Puls I, Hermann D, et al. Amygdala-prefrontal coupling depends on a genetic variation of the serotonin transporter. Nat Neurosci 2005; 8: 20-1.

39 Taylor SE, Way BM, Welch WT, Hilmert CJ, Lehman BJ, Eisenberger NI. Early family environment, current adversity, the serotonin transporter promoter polymorphism, and depressive symptomatology. Biol Psychiatry 2006; 60: 671-6

40 Surtees PG, Wainwright NW, Willis-Owen SA, Luben R, Day NE, Flint J. Social adversity, the serotonin transporter (5-HTTLR) polymorphism and major depressive disorder. Biol Psychiatry 2006; 59: 224-9.

41 Cooper RS. Gene-environment interactions and the etiology of common complex disease. Ann Intern Med 2003; 139: 437-40.

42 Kruijshaar ME, Barendregt J, Vos T, de Graaf R, Spijker J, Andrews G. Lifetime prevalence estimates of major depression: an indirect estimation method and a quantification of recall bias. Eur J Epidemiol 2005; 20: 103-11.

\section{0 words}

\section{Melancholia}

\section{Alistair Stewart}

'I got stones in my pathway/And my road seems dark at night/I have pains in my heart/They have taken my appetite'. Robert Johnson, known as the King of the Delta blues singers, distilled into these lines the essence of severe depressive illness - somatic ills, fear and suspicion, emotional and physical pain, nocturnal troubles and struggle against obstacles. The words are one with the powerful, haunting music. ICD-10 and DSM-IV have their place, but poets have often been there before us, and done a better job. We can all learn from Robert Johnson, born just 100 years ago. 